\title{
Identifying term breast-fed infants at risk of significant hyperbilirubinemia
}

\author{
Pi-Feng Chang ${ }^{1,2}$, Yu-Cheng Lin ${ }^{1,2}$, Kevin Liu', Shu-Jen Yeh' and Yen-Hsuan $\mathrm{Ni}^{3}$
}

BACKGROUND:The aim of this study was to establish a model to identify term breast-fed infants who are at risk of developing significant neonatal hyperbilirubinemia.

METHODS: A prospective study was designed to investigate the effects of birth weight, mode of delivery, cephalohematoma, glucose-6-phosphate dehydrogenase (G6PD) deficiency, predischarge total serum bilirubin, variant uridine 5'diphospho-glucuronosyltransferase 1A1 (UGT1A1) gene, and hepatic solute carrier organic anion transporter 1B1 (SLCO1B1) gene on significant hyperbilirubinemia in term breast-fed neonates. Significant hyperbilirubinemia was defined as a bilirubin level exceeding the hour-specific phototherapy treatment threshold recommended by the American Academy of Pediatrics in 2004.

RESULTS: Of 240 exclusively breast-fed term neonates, 26 (10.8\%) had significant hyperbilirubinemia. The predischarge total serum bilirubin on the third day (odds ratio $(\mathrm{OR})=2.63$; 95\% confidence interval $(\mathrm{Cl}): 1.87-3.70 ; P<0.001)$ and the variant UGT1A1 gene at nucleotide 211 (OR $=5.00 ; 95 \% \mathrm{Cl}: 1.08-$ 23.03; $P<0.05)$ were significant risk factors. The area under the receiver operating characteristic (ROC) curve of the predictive probability was 0.964 (95\% Cl: 0.932-0.984; $P<0.0001$ ).

CONCLUSION: Combining the total serum bilirubin on the third day and the variant UGT1A1 gene at nucleotide 211 can predict hyperbilirubinemia well in term breast-fed infants.

nfants who are breast-fed have higher serum bilirubin levels than infants who are formula-fed (1). In recent years, the policy of exclusive breastfeeding and a short hospitalization has been associated with hyperbilirubinemia and kernicterus in term neonates (2). The incidences of severe hyperbilirubinemia and kernicterus are high in Asian infants (3). These data suggest that demographic, environmental, and genetic factors are involved in the development of hyperbilirubinemia in breast-fed neonates. In breast-fed neonates, variants in uridine 5'diphospho-glucuronosyltransferase 1A1 (UGT1A1) at nucleotide position 211, glucose-6-phosphate dehydrogenase (G6PD) deficiency, and hepatic solute carrier organic anion transporter 1B1 (SLCO1B1) are all known risk factors for hyperbilirubinemia (4-7). Infants who are healthy at discharge may not be exempt from subsequent severe hyperbilirubinemia.
Recognition of breast-fed neonates with high risk for significant hyperbilirubinemia is important to avoid bilirubin toxicity. We need to establish a predictive model for significant hyperbilirubinemia when the newborns are discharged from the hospital. We hypothesized that bilirubin levels on the third day, birth weight, sex, mode of delivery, G6PD deficiency, variant UGT1A1 gene, and SLCO1B1 gene are risk factors and aimed to set up a diagnostic model to predict significant hyperbilirubinemia in Taiwanese breast-fed neonates.

\section{RESULTS}

A total of 240 breast-fed term neonates (123 males and 117 females) were enrolled in this study. Among these 240 neonates, 26 (10.8\%, 18 males and 8 females) infants had significant hyperbilirubinemia. The remaining 214 breast-fed neonates (105 males and 109 females) without hyperbilirubinemia served as control infants (Figure 1). Birth weight, the percentage of weight loss, gestational age, maternal age, Apgar score, sex, and cephalohematoma were not significantly different between the hyperbilirubinemia and control groups. G6PD deficiency was significantly different between the study and the control groups (Table 1). The G6PD-deficient subjects were 1 male and 3 female infants. In the phototherapy group, there were 1 male and 2 female G6PD-deficient babies.

The UGT1A1 gene (wild-type; variation in promoter; variations at nucleotides 211,686, 1091, and 1456; and compound heterozygous variation) and the variations at nucleotide 388 and 521 of SLCO1B1 gene were identified in the hyperbilirubinemia and control groups (Table 2). Thirteen of 26 (50\%) breast-fed infants with significant hyperbilirubinemia had at least one mutation of the UGT1A1 gene. The percentage of the neonates having the variant nucleotide 211 was significantly different between the hyperbilirubinemia and control groups (Table 2). Eleven of 26 (42.3\%) breast-fed infants with hyperbilirubinemia had mutation of nucleotide 211. Variation at nucleotide 211 of UGT1A1 gene is the most common mutation associated with hyperbilirubinemia.

The results of the multivariate logistic regression model revealed that the total serum bilirubin (TSB) on the third day (odds ratio $(\mathrm{OR})=2.63$; 95\% confidence interval $(\mathrm{CI})$ : $1.87-$ 3.70; $P<0.001)$ and the variant UGT1A1 gene at nucleotide 


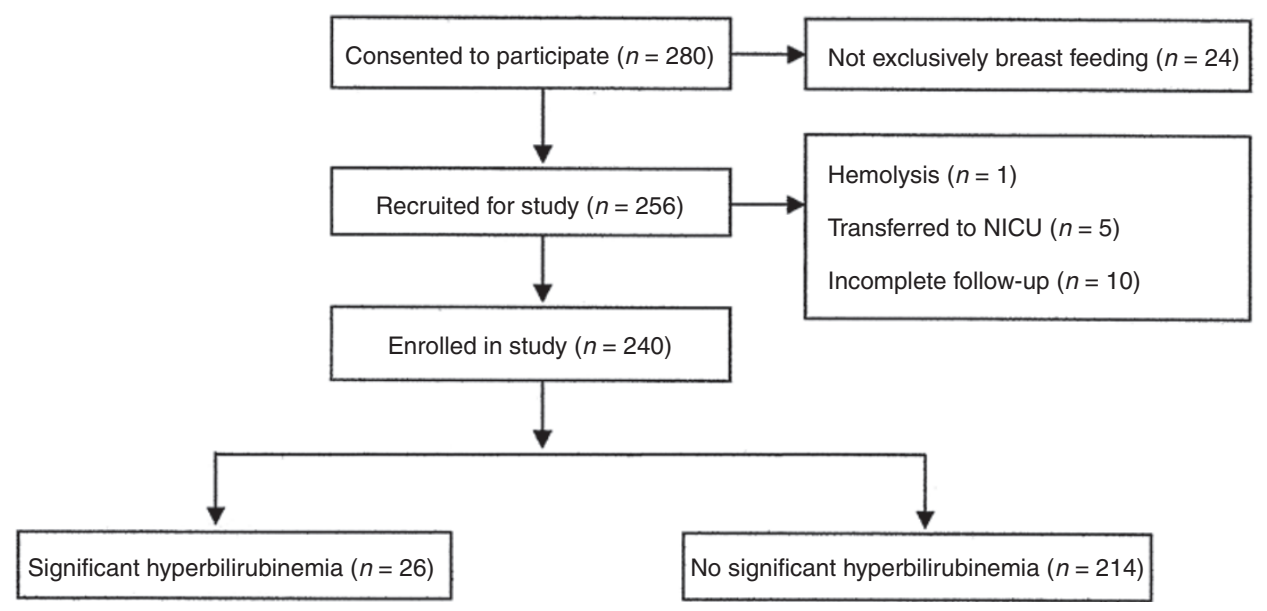

Figure 1. Assembly of study sample. NICU, neonatal intensive care unit.

Table 1. The demographic characteristics of the hyperbilirubinemia and control groups

\begin{tabular}{lcc}
\hline & $\begin{array}{c}\text { Hyperbilirubinemia } \\
(n=26)\end{array}$ & $\begin{array}{c}\text { Control } \\
(n=214)\end{array}$ \\
\hline Gestational age (wk) & $38.6 \pm 1.1$ & $38.9 \pm 1.1$ \\
Birth weight (g) & $3,294.8 \pm 314.7$ & $3,224.1 \pm 460.2$ \\
Weight loss (\%) & $3.1 \pm 4.6$ & $3.5 \pm 6.5$ \\
Maternal age (y) & $30.8 \pm 4.9$ & $30.4 \pm 4.4$ \\
Apgar score (at 5 min) & $9.1 \pm 0.3$ & $9.1 \pm 0.8$ \\
Sex (male/female) & $18 / 8$ & $105 / 109$ \\
Cephalohematoma & 0 & 2 \\
Delivery mode & $20 / 6$ & $137 / 77$ \\
(vaginal/cesarean) & & $1 *$ \\
G6PD deficiency & $3^{*}$ & \\
\hline G6PD, glucose-6-phosphate dehydrogenase. & \\
*P<0.05 for comparison with hyperbilirubinemia and control groups.
\end{tabular}

$211(\mathrm{OR}=5.00 ; 95 \%$ CI: 1.08-23.03; $P<0.05)$ were independent factors for significant hyperbilirubinemia in breast-fed neonates (Table 3). The area under the receiver operating characteristic (ROC) curve (AUC) of the predictive probability was 0.964 (95\% CI: 0.932-0.984; $P<0.0001$ ).

The formula for the predictive probability $(P)$ is as follows:

$\operatorname{Ln}(P / 1-P)=-16.098+0.967 \times \mathrm{TBIL}(\mathrm{mg} / \mathrm{dl})+1.609 \times \mathrm{NT} 211$

( 0 point for no variation, and 1 point for variation)

where $\mathrm{Ln}$ is the natural logarithm, TBIL is TSB on the third day, and NT 211 is the variation at nucleotide 211 of UGT1A1 gene. On the basis of the different TSB values on the third day and the status of variant nucleotide 211 in UGT1A1 gene, the probability of subsequent hyperbilirubinemia could be given as shown in Table 4. If the goal of screening is to identify all true significant hyperbilirubinemia, then a relatively low probability needs to be used as the positivity criterion. For example, using a probability of 0.35 as the positivity criterion could identify $73 \%$ of infants who would develop significant hyperbilirubinemia (i.e., sensitivity $=0.73$ ). More stringent
Table 2. Variations in UGT1A1 gene and SLCO1B1 gene among breast-fed newborn infants with hyperbilirubinemia and controls

\begin{tabular}{|c|c|c|}
\hline & $\begin{array}{l}\text { Hyperbilirubinemia } \\
\quad(n=26)\end{array}$ & $\begin{array}{l}\text { Control } \\
(n=214)\end{array}$ \\
\hline \multicolumn{3}{|l|}{ Variant UGT1A1 gene } \\
\hline Wild type & $13(50 \%)$ & $127(59.3 \%)$ \\
\hline Promoter & $1(3.8 \%)$ & $20(9.3 \%)$ \\
\hline Nucleotide $211 \mathrm{G}$ to $\mathrm{A}$ & $11(42.3 \%)^{*}$ & $51(23.8 \%)^{*}$ \\
\hline $211 \mathrm{G}$ to $\mathrm{A} /$ normal & 10 & 45 \\
\hline $211 \mathrm{G}$ to $\mathrm{A} / 211 \mathrm{G}$ to $\mathrm{A}$ & 1 & 6 \\
\hline Nucleotide $686 \mathrm{C}$ to $\mathrm{A}$ & $0(0 \%)$ & $6(2.8 \%)$ \\
\hline Nucleotide $1091 \mathrm{C}$ to $\mathrm{T}$ & $0(0 \%)$ & $4(1.9 \%)$ \\
\hline Nucleotide $1456 \mathrm{~T}$ to $\mathrm{G}$ & $0(0 \%)$ & $1(0.5 \%)$ \\
\hline Compound variations & $1(3.8 \%)$ & $5(2.3 \%)$ \\
\hline $6 / 7,1091 \mathrm{C}$ to $\mathrm{T} /$ normal & 1 & 0 \\
\hline $\begin{array}{l}211 \mathrm{G} \text { to } \mathrm{A} / \text { normal, } 686 \mathrm{C} \text { to } \\
\mathrm{A} / \text { normal }\end{array}$ & 0 & 2 \\
\hline $\begin{array}{l}211 \mathrm{G} \text { to } \mathrm{A} / \text { normal, } 1091 \mathrm{C} \text { to } \\
\mathrm{T} / \text { normal }\end{array}$ & 0 & 1 \\
\hline $1091 \mathrm{C}$ to $\mathrm{T}, 1456 \mathrm{~T}$ to $\mathrm{G}$ & 0 & 2 \\
\hline \multicolumn{3}{|l|}{ Variant $S L C O 1 B 1$ gene } \\
\hline Nucleotide 388 A to G & $11(42.3 \%)$ & $80(37.4 \%)$ \\
\hline Nucleotide $521 \mathrm{~T}$ to $\mathrm{C}$ & $2(7.7 \%)$ & $24(11.2 \%)$ \\
\hline Compound variations & $1(3.8 \%)$ & $10(4.7 \%)$ \\
\hline $\begin{array}{l}\text { Coexpression of UGT1A1 and } \\
\text { SLCO1B1 }\end{array}$ & $7(26.9 \%)$ & $44(20.6 \%)$ \\
\hline $\begin{array}{l}\text { G6PD deficiency with } \\
\text { coexpression of UGT1A1 and } \\
\text { SLCO1B1 }\end{array}$ & $1(3.8 \%)$ & $0(0 \%)$ \\
\hline
\end{tabular}

${ }^{*} P<0.05$ for comparison with hyperbilirubinemia and control groups.

positivity criteria (i.e., higher probability thresholds) may give an improved specificity and a decline in sensitivity (Table 4). The AUC for predicting jaundice in healthy term breast-fed infants was 0.964 (95\% CI: 0.932-0.984; $P<0.0001)$. The AUC of predictive probability from the 10 -fold cross-validation method was 0.950 (95\% CI: 0.915-0.914; $P<0.0001$ ). The predictive performance (AUC) from the final model was the same 
Table 3. Logistic regression models for variables associated with significant hyperbilirubinemia of breast-fed infants

\begin{tabular}{lccccc}
\hline & \multicolumn{2}{c}{ UV } & & \multicolumn{2}{c}{$\mathrm{MV}$} \\
\cline { 2 - 3 } \cline { 5 - 6 } Variables & OR & $95 \% \mathrm{Cl}$ & & OR & $95 \% \mathrm{Cl}$ \\
\hline Predischarge TSB & $2.46^{* *}$ & $1.81-3.35$ & & $2.63^{* *}$ & $1.87-3.70$ \\
G6PD deficiency & $27.78^{*}$ & $2.79-279.44$ & & \\
Vaginal delivery & 1.87 & $0.72-4.86$ & & \\
Variant UGT1A1 gene & & & & & \\
$\quad$ Wild type & 0.69 & $0.30-1.55$ & & \\
$\quad \begin{array}{l}\text { Promoter } \\
\text { Nucleotide 211 }\end{array}$ & 0.39 & $0.50-3.02$ & & \\
$\quad \begin{array}{l}\text { Compound } \\
\text { heterozygous }\end{array}$ & $1.34^{*}$ & $1.01-5.43$ & & $5.00^{*}$ & $1.08-23.03$ \\
Variant SLCO1B1 gene & & $0.19-14.89$ & & \\
$\quad$ Nucleotide 388 & 1.23 & $0.54-2.81$ & & \\
$\quad$ Nucleotide 521 & 0.66 & $0.15-2.97$ & & \\
$\quad \begin{array}{l}\text { Compound } \\
\text { variations }\end{array}$ & 0.82 & $0.10-6.65$ & & \\
\hline
\end{tabular}

Cl, confidence interval; G6PD, glucose-6-phosphate dehydrogenase; MV, multivariate analysis; $\mathrm{OR}$, odds ratio; $\mathrm{TSB}$, total serum bilirubin; $\mathrm{UV}$, univariate analysis. * $P<0.05$; ${ }^{* *} P<0.001$

Table 4. Predictive probability of subsequent significant hyperbilirubinemia in breast-fed infants

\begin{tabular}{lcccccc}
\hline $\begin{array}{l}\text { TBIL } \\
(\mathrm{mg} / \mathrm{dl})\end{array}$ & $\begin{array}{c}\text { Variant } \\
\text { NT 211 }\end{array}$ & $\begin{array}{c}\text { Predictive } \\
\text { probability }\end{array}$ & $\begin{array}{c}\text { Sn } \\
(\%)\end{array}$ & $\begin{array}{c}\text { Sp } \\
(\%)\end{array}$ & $\begin{array}{c}\text { PPV } \\
(\%)\end{array}$ & $\begin{array}{c}\text { NPV } \\
(\%)\end{array}$ \\
\hline 16 & 0 & 0.35 & 73.1 & 96.2 & 67.9 & 96.7 \\
& 1 & 0.73 & 50.0 & 99.1 & 86.7 & 94.2 \\
16.5 & 0 & 0.46 & 65.4 & 97.7 & 77.2 & 95.9 \\
& 1 & 0.81 & 50.0 & 100 & 100 & 94.3 \\
17 & 0 & 0.58 & 61.5 & 99.1 & 88.9 & 95.5 \\
& 1 & 0.88 & 38.5 & 100 & 100 & 93.0 \\
17.5 & 0 & 0.70 & 50.0 & 99.1 & 86.7 & 94.2 \\
& 1 & 0.92 & 30.8 & 100 & 100 & 92.2 \\
18 & 0 & 0.79 & 50.0 & 100 & 100 & 94.3 \\
& 1 & 0.95 & 26.9 & 100 & 100 & 91.8 \\
18.5 & 0 & 0.86 & 42.3 & 100 & 100 & 93.5 \\
& 1 & 0.97 & 23.1 & 100 & 100 & 91.5 \\
19 & 0 & 0.91 & 30.8 & 100 & 100 & 92.2 \\
& 1 & 0.98 & 23.1 & 100 & 100 & 91.5 \\
\hline
\end{tabular}

NPV, negative predictive value; NT 211, nucleotide 211 in UGT1A1: 0 points for no variation and 1 point for variation; PPV, positive predictive value; $S n$, sensitivity; Sp, specificity; TBIL, total serum bilirubin level at the third day.

as that of 10 -fold cross-validation $(Z$ statistic $=2.085$; probability of difference between the two AUCs = 0.037) (Figure 2).

\section{DISCUSSION}

Numerous studies have reported an association between breastfeeding and an increased incidence and severity of hyperbilirubinemia, both within the first few days of life (8-11). Breast-fed infants in Taiwan presumably have significantly

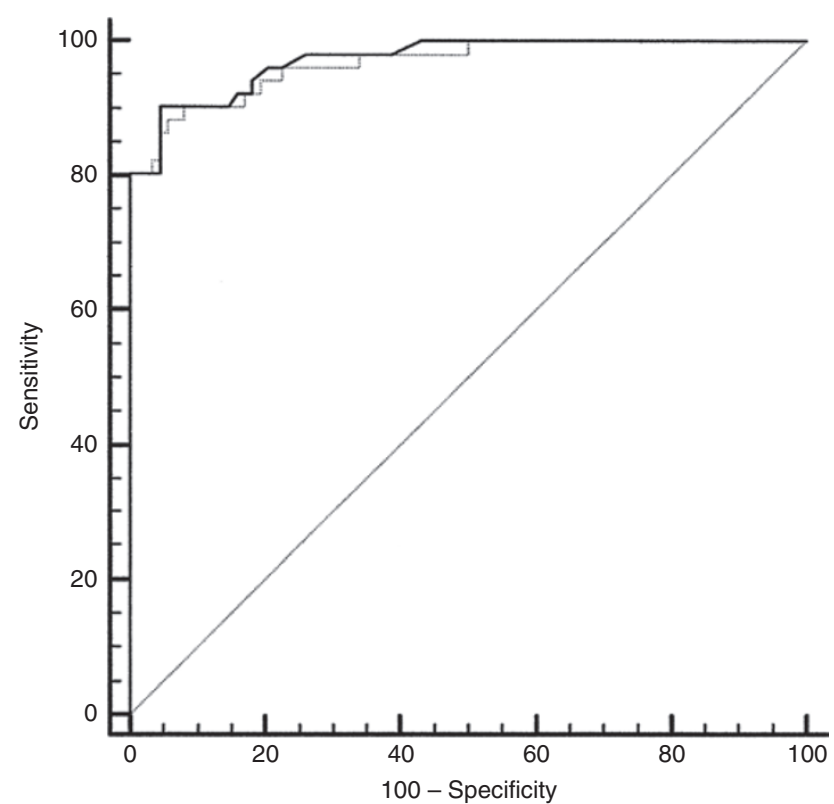

Figure 2. The comparison result of AUC from final model (solid line) was the same as that of 10 -fold cross-validation (dashed line). AUC, area under the receiver operating characteristic curve.

higher bilirubin levels than do breast-fed infants in the United States or in Europe, so that when we use US criteria for initiating phototherapy, $\sim 11 \%$ of our breast-fed infants require phototherapy, which is about double the number who receive phototherapy in the United States.

In our study, we found that the combination of TSB values on the third day and variation at nucleotide 211 of the UGT1A1 gene could predict the risk of significant hyperbilirubinemia. Of note, some risk factors listed in previous reports, including G6PD deficiency, were not found to be significant predictors of hyperbilirubinemia in this study (7). It is not surprising that G6PD deficiency did not enter the model because there were very few babies with this condition. If the infant had a higher predischarge bilirubin level and the $211 \mathrm{G}$-to-A variation in the UGT1A1 gene, a clinician could expect that infant to be at risk of developing significant hyperbilirubinemia. Previous studies suggested that the predischarge bilirubin level is a good predictive factor for significant neonatal hyperbilirubinemia (12-18). The effect of gestational age on the risk of subsequent hyperbilirubinemia is well documented and quite profound. The measurement of the predischarge bilirubin is a powerful predictor of subsequent hyperbilirubinemia and, when combined with gestational age, is even more powerful (13-15). However, our subjects were "full-term" healthy babies (gestational age $\geq 37$ weeks), and there are only 26 cases in our study, so it is not surprising that we cannot find the relationship between gestational age and the risk of subsequent hyperbilirubinemia. It might be a type II error. In this study, we prospectively built a multivariable logistic regression model to predict development of significant hyperbilirubinemia in healthy term breast-fed infants using clinical risk factors and predischarge bilirubin values. Our model can estimate the risk of subsequent clinically significant hyperbilirubinemia as high 
(probability $>0.75)$, intermediate $(0.5 \leq$ probability $\leq 0.75)$, or low (probability $<0.5$ ). We recommend that high-risk neonates return within $48 \mathrm{~h}$ of discharge, and that intermediaterisk neonates be scheduled to return between 48 and $72 \mathrm{~h}$ of discharge, whereas those with low risk can return to visit after longer intervals. We recommend this risk-based guideline for evaluation, intervention, and follow-up.

The results of our study revealed that variation at nucleotide 211 of the UGT1A1 gene is the most common mutation associated with hyperbilirubinemia in breast-fed infants. On the other hand, the percentage of A(TA) $)_{7}$ TAA in breast-fed neonates with hyperbilirubinemia was not different from that of healthy control infants, which is different from the previous findings in Caucasians (7,19-21). These ethnic differences were also observed in the Chinese and Japanese populations $(22,23)$. This suggests that breastfeeding may act as an external factor for certain variant genotypes predisposing to the development of hyperbilirubinemia. The breast-fed neonates who carry variant 211 in the UGT1A1 gene had increased risk of the development of hyperbilirubinemia (7). Our results suggest that if DNA-based test results could be made available before discharge, they may be helpful in predicting the risk of hyperbilirubinemia requiring phototherapy. In our institution, the cost of detection of one "hot spot" mutation site of the UGT1A1 gene (such as nucleotide 211) is $300 \mathrm{New}$ Taiwan dollars (equal to 10 US dollars). The UGT screening could be a staged testing based on bilirubin level. For example, a term breast-fed infant with a bilirubin level of $16.5 \mathrm{mg} / \mathrm{dl}$ on the third day and no variant 211 in the UGT1A1 gene would have a predictive probability of 0.46 , placing this baby in the low-risk group of developing significant hyperbilirubinemia. If an infant who carried variant 211 in the UGT1A1 gene had a bilirubin level of $16.5 \mathrm{mg} / \mathrm{dl}$ on the third day, a clinician could predict that the infant is in the high-risk group, with a significantly higher probability (0.81) of developing significant hyperbilirubinemia after discharge (Table 4). Application of this model would predict significant hyperbilirubinemia in Asian breast-fed infants to prevent bilirubin toxicity.

\section{Conclusion}

Although bilirubin screening before discharge is very important, it is not sufficient and must be combined with the assessment of clinical risk factors. Combination of the predischarge bilirubin values on the third day and variation at nucleotide 211 of the UGT1A1 gene can predict the development of significant hyperbilirubinemia accurately.

\section{METHODS}

From 1 April 2008 to 31 October 2011, term ( $\geq 37$ wk gestation) Taiwanese neonates who were exclusively fed breast milk were recruited in Far Eastern Memorial Hospital, New Taipei City. The breastfeeding rate at our hospital is $>90 \%$. This study was approved by the institutional research board of the Far Eastern Memorial Hospital, New Taipei, Taiwan. All the parents, either of study group infants or of control group infants, gave informed consent to let their babies participate this study for surveillance of the UGT1A1 gene and the SLCO1B1 gene. A prospective cohort study was conducted to investigate the effects of birth weight, sex, mode of delivery, G6PD deficiency, variant UGT1A1 gene, and SLCO1B1 gene on hyperbilirubinemia in Taiwanese breast-fed neonates. All term breast-fed babies routinely underwent blood sampling to do newborn screening for inborn errors of metabolism by tandem mass spectrometry. In the meantime, the analyses of TSB levels were obtained on the third day (between 64 and $72 \mathrm{~h}$ postnatal life) before they were discharged from the hospital. A return visit was recommended for all neonates. The follow-up total serum bilirubin levels were obtained within $24-48 \mathrm{~h}$ after discharge and later if indicated. All neonates received outpatient follow-up until bilirubin levels declined. In our study, blood types $(\mathrm{ABO}$ and $\mathrm{Rh})$ and a quantitative spectrophotometric analysis of G6PD were routinely checked to exclude $\mathrm{ABO}$ or Rh incompatibility and G6PD deficiency. The pediatricians check babies every day. If the clinician identified any babies who possibly had pathologic jaundice, these babies would receive blood tests before $64 \mathrm{~h}$ of life to exclude hemolytic anemia, hypoalbuminemia, G6PD deficiency, sepsis, liver diseases, and hypothyroidism.

Universal G6PD screening has been implemented nationwide in Taiwan since 1987. A quantitative spectrophotometric analysis with the PerkinElmer Neonatal G6PD Kit (ND-1000; PerkinElmer, Boston, MA) was used to diagnose G6PD deficiency. The diagnostic threshold was $\leq 2.9 \mathrm{U} / \mathrm{gHb}$ (24). For the UGT1A1 and SLCO1B1 genes, total genomic DNA was isolated from cord blood cells using a blood DNA isolation kit (Maxim Biotech, San Francisco, CA). The PCR restriction fragment length polymorphism method was used to detect the known variant sites (A(TA) ${ }_{7}$ TAA promoter variant and nucleotides $211,686,1091$, and 1456) in the UGT1A1 gene and the two known variants (nucleotides 388 and 521) of the SLCO1B1 gene in Taiwanese $(4,25)$. The PCR amplification was performed in a DNA thermal cycler (PerkinElmer Cetus, Norwalk, CT) as described previously $(4,25,26)$. If the bilirubin level exceeded the hour-specific phototherapy treatment threshold recommended by the American Academy of Pediatrics in 2004 (27), the clinician made the decision to start phototherapy. These neonates were assessed until bilirubin levels declined.

We analyzed the data with IBM SPSS statistics software, version 19.0 (SPSS, Chicago, IL) and MedCalc software, version 12.3.0.0 (MedCalc, Mariakerke, Belgium). The clinical risk factors were examined using $t$-tests for continuous predictors and Pearson $\chi^{2}$ and Fisher exact tests for categorical predictors. A forward stepwise logistic regression analysis was performed to identify risk factors for hyperbilirubinemia in healthy term breast-fed infants. ORs and 95\% CIs for various risk factors were estimated with multiple logistic regression models. A $P$ value $<0.05$ or a $95 \%$ CI for OR $>1.0$ was defined as statistically significant. Variables were entered into the model and removed at a cutoff $P$ value of 0.05 . We plotted a ROC curve and estimated the AUC to assess the predictive accuracy of this final model. The performance of this final model was evaluated using a 10 -fold cross-validation method. All 240 breast-fed neonates were randomly divided into 10 subsets of almost equal size. Nine subsets were used for training, and the remaining subset was used for testing. We ran this procedure 10 times; each time we picked a different subset for testing and the nine remaining subsets for training. Therefore, we acquired a predictive probability for every observation after testing. Finally, the ROC curve was obtained by the probability. The AUC from the final model and 10 -fold cross-validation method were compared.

\section{STATEMENT OF FINANCIAL SUPPORT}

This work was supported by grants from Far Eastern Memorial Hospital (FEMH -97-C-028 and FEMH- 2012-C-040).

\section{REFERENCES}

1. Gourley GR. Breast-feeding, neonatal jaundice and kernicterus. Semin Neonatol 2002;7:135-41.

2. Johnson L, Bhutani VK. Guidelines for management of the jaundiced term and near-term infant. Clin Perinatol 1998;25:555-74, viii.

3. Ives NK. Neonatal jaundice. In: Rennie JM, Roberton NRC, eds. Textbook of Neonatology. Edinburgh, UK: Churchill-Livingston, 1999:715-32.

4. Huang MJ, Kua KE, Teng HC, Tang KS, Weng HW, Huang CS. Risk factors for severe hyperbilirubinemia in neonates. Pediatr Res 2004;56:682-9. 
5. Chang PF, Lin YC, Liu K, Yeh SJ, Ni YH. Prolonged unconjugated hyperbiliriubinemia in breast-fed male infants with a mutation of uridine diphosphate-glucuronosyl transferase. J Pediatr 2009;155:860-3.

6. Kaplan M, Herschel M, Hammerman C, Hoyer JD, Heller GZ, Stevenson DK. Neonatal hyperbilirubinemia in African American males: the importance of glucose-6-phosphate dehydrogenase deficiency. J Pediatr 2006;149:83-8.

7. Chang PF, Lin YC, Liu K, Yeh SJ, Ni YH. Risk of hyperbilirubinemia in breast-fed infants. J Pediatr 2011;159:561-5.

8. Linn S, Schoenbaum SC, Monson RR, Rosner B, Stubblefield PG, Ryan KJ. Epidemiology of neonatal hyperbilirubinemia. Pediatrics 1985;75:770-4.

9. Maisels MJ, Gifford K. Normal serum bilirubin levels in the newborn and the effect of breast-feeding. Pediatrics 1986;78:837-43.

10. Schneider AP 2nd. Breast milk jaundice in the newborn. A real entity. JAMA 1986;255:3270-4.

11. Hansen TW. Bilirubin production, breast-feeding and neonatal jaundice. Acta Paediatr 2001;90:716-7.

12. Keren R, Bhutani VK, Luan X, Nihtianova S, Cnaan A, Schwartz JS. Identifying newborns at risk of significant hyperbilirubinaemia: a comparison of two recommended approaches. Arch Dis Child 2005;90:415-21.

13. Newman TB, Liljestrand P, Escobar GJ. Combining clinical risk factors with serum bilirubin levels to predict hyperbilirubinemia in newborns. Arch Pediatr Adolesc Med 2005;159:113-9.

14. Keren R, Luan X, Friedman S, Saddlemire S, Cnaan A, Bhutani VK. A comparison of alternative risk-assessment strategies for predicting significant neonatal hyperbilirubinemia in term and near-term infants. Pediatrics 2008;121:e170-9.

15. Maisels MJ, Deridder JM, Kring EA, Balasubramaniam M. Routine transcutaneous bilirubin measurements combined with clinical risk factors improve the prediction of subsequent hyperbilirubinemia. J Perinatol 2009;29:612-7.

16. Bhutani VK, Johnson L, Sivieri EM. Predictive ability of a predischarge hour-specific serum bilirubin for subsequent significant hyperbilirubinemia in healthy term and near-term newborns. Pediatrics 1999;103:6-14.
17. Stevenson DK, Fanaroff AA, Maisels MJ, et al. Prediction of hyperbilirubinemia in near-term and term infants. Pediatrics 2001;108:31-9.

18. Kaplan M, Hammerman C, Feldman R, Brisk R. Predischarge bilirubin screening in glucose-6-phosphate dehydrogenase-deficient neonates. Pediatrics 2000;105(3 Pt 1):533-7.

19. Kaplan M, Renbaum P, Levy-Lahad E, Hammerman C, Lahad A, Beutler E. Gilbert syndrome and glucose-6-phosphate dehydrogenase deficiency: a dose-dependent genetic interaction crucial to neonatal hyperbilirubinemia. Proc Natl Acad Sci USA 1997;94:12128-32.

20. Bancroft JD, Kreamer B, Gourley GR. Gilbert syndrome accelerates development of neonatal jaundice. J Pediatr 1998;132:656-60.

21. Cappellini MD, Martinez di Montemuros F, Sampietro M, Tavazzi D, Fiorelli G. The interaction between Gilbert's syndrome and G6PD deficiency influences bilirubin levels. Br J Haematol 1999;104:928-9.

22. Sun G, Wu M, Cao J, Du L. Cord blood bilirubin level in relation to bilirubin UDP-glucuronosyltransferase gene missense allele in Chinese neonates. Acta Paediatr 2007;96:1622-5.

23. Akaba K, Kimura T, Sasaki A, et al. Neonatal hyperbilirubinemia and a common mutation of the bilirubin uridine diphosphate-glucuronosyltransferase gene in Japanese. J Hum Genet 1999;44:22-5.

24. Chiang SH, Fan ML, Hsiao KJ. External quality assurance programme for newborn screening of glucose-6-phosphate dehydrogenase deficiency. Ann Acad Med Singap 2008;37:Suppl 12:84-4.

25. Huang CS, Chang PF, Huang MJ, Chen ES, Hung KL. Relationship between bilirubin UDP-glucuronosyltransferase 1A1 gene and neonatal hyperbilirubinemia. Pediatr Res 2002;52:601-5.

26. Huang CS, Chang PF, Huang MJ, Chen ES, Chen WC. Glucose-6-phosphate dehydrogenase deficiency, the UDP-glucuronosyl transferase $1 \mathrm{Al}$ gene, and neonatal hyperbilirubinemia. Gastroenterology 2002;123: 127-33.

27. American Academy of Pediatrics. Management of hyperbilirubinemia in the newborn infant 35 or more weeks of gestation. Pediatrics 2004;114: 297-316. 